\title{
Measurement of odours by sensory analysis or "olfactometry"
}

\author{
A.M. Gouronnec*, V. Tomasso \\ Institut de Protection et de Sûreté Nucléaire, CEA/Saclay, Bât. 389, 91191 Gif-sur-Yvette Cedex, France
}

\begin{abstract}
Olfactometry or measurement of odours by sensory analysis is used to quantify odours. The available methods are used to measure three variables: odour concentration, odour intensity and odour annoyance. The first two variables are measured by a panel of pre-selected experts and the third relies on a local population panel. Measurement of these three variables can characterise the different odour sources of a site and compare them; it can also characterise the environment of the source of odour.
\end{abstract}

human olfactory systems that often perceive chemical signals corresponding to such tiny molecular concentrations that they aren't detected by current chemical analysers. Olfactometry also allows for the integration of the properties of the nasal mucous membrane for mixtures of odorous molecules. In fact, when the mucous membrane is subjected to a mixture of molecules, there may be a resultant inhibition or exacerbation of the odour signals that would have been obtained from molecules taken separately.

Therefore, both types of analysis are complementary since one provides knowledge of the composition of the mixture studied while the other answers the question: "is an odour being given off and, if so, how much ?".

\section{The measurement "device"}

The properties of the human olfactory sense organs are so complex that no sensor is currently able to exactly reproduce them. This is why the only operational measurement "device" to detect the odours derived from industrial processes (moist, dusty, complex gases, etc.) is still the human nose.

For this reason, measurement methods are based on sensory analysis. These methods rely on serious scientific foundations and may be used deliberately in industry. They take inter-individual differences into account since they rely on a panel of "sniffers" rather than on an isolated individual. Then, in olfactometry, a measurement result is always based on two items of information: a mean value and a standard deviation which are the reflection of inter-individual differences in perception for the gaseous mixture studied.

The individuals included on a panel have to be selected in order to verify that their olfactory perception is representative of the standard population. The aim of the selection is to detect and remove of the panel people that have been found to suffer from anosmia or who are hyper-sensitive to certain chemical substances. In fact, these individuals are rare in the general population (several per cent). They help considerably distort the results if they are included in a population sample reduced to under ten subjects and supposed to be representative of the population. The selection, described in french standards AFNOR NF X 43-101 [1] and NF X 43-103 [2], includes two types of tests: 
- the first consists in correctly classifying, by order of odour intensity (see later), solutions of butan-1-ol or pyridine in water; the concentrations of these solutions are evenly distributed in a series from 1 to 1000;

- the assessors are then qualified according to their individual perception threshold (see later) for five pure chemical compound (butan-1-ol, hexan-2-one, pyridine, propionic acid and tetrahydrothiophene); for each of these compounds, the individual perception threshold of the assessors should fall within a range of 0.1 to 10 times the perception threshold provided as a reference. That confirms that the aim of the selection is not to keep the most sensitive assessors. This qualification is verified on a regular basis.

For the analysis of a gas sample, the operator chooses as far as possible panel members with demonstrated individual perception thresholds that are dispersed in a homogenous manner. The representativeness of the population sample formed by the panel depends directly on the number of the members: the higher is the number of panel members, the more reproducible and reliable is the measurement. Therefore, a compromise has to be reached between the cost and the validity of the results. At least 16 panel members is recommended if a good precision on the measurement result is required, 6 to 8 panel members in most cases and 4 panel members for comparative measurements.

\section{Sampling}

The sampling of odorants is an important part in measuring the odour. It conditions the quality and reliability of the results of the measurement. In France, standard NF X 43-104 [3] describes different gas sampling procedures according to the type of source and analysis, as well as the conditions for the storage and the transport of the samples. The methods described in this standard include odorous atmospheres and then apply to olfactometric analysis (sensory analysis) as to physico-chemical analysis.

The sources of odour can be release from stack (channelled sources), surface of a liquid, semi-liquid or solid material (diffuse sources such as lagoons, basins in sewage treatment plants, etc.) or the whole of a building with all of its openings when the release are not channelled.

In the case of channelled sources or buildings with openings, the sampling probe is introduced in the gas studied that means in the release stack or directly in the ambient air of the building.

In the case of diffuse sources, whether or not artificially aerated, a mobile hood is placed on the emitting surface in order to eliminate the influence of the wind. In the case of a surface artificially aerated, the sampling probe is introduced in the hood and the gas sampled is that given off by the surface, without any random dilution by the wind. If the emitting surface isn't crossed by an air flow, the odour emission is due to the sweeping of the surface by the wind. Then, for sampling purposes, artificial sweeping with clean air is created above the surface covered by the hood and the air sampled is the sweeping air loaded in odorous molecules coming from the emitting surface.

In the above-mentioned standard, two types of olfactometries are presented:

- in line olfactometry (after dynamic sampling) where the gas is directly ducted from the place of sampling to the olfactometer used to present the sample to the experts (see later). It is used for constant odorous emissions. The advantage is that there is no time between sampling and analysis. The disadvantage is the need to isolate the measurement premises from the odour surrounding the site and also to send the team of experts to the site as this is expensive;

- the differed olfactometry (after static sampling) where the sampled gas is stored in sampling bags. This is used for constant or non constant odorous emissions. The conditions for the storage and transport of the sample should be suitable. The advantage is that the analysis can be carried out in laboratory conditions, without additional cost since the experts are on the spot. The disadvantage lies in the time between sampling and analysis, which is limited to 30 hours.

\section{The different types of measurements [4-7]}

Olfactometric analysis provides different variables: the odour concentration and the odour intensity. A third variable can also be measured: the odour annoyance. As we will see, this one is not measured by a panel of pre-selected members but by people that have not been previously selected. The characteristics of each of the variables are summed up in table I.

\section{Odour concentration}

The odour concentration of any odorous gas mixture is defined with respect to its "odour concentration at the perception threshold". By convention, the latter is the concentration of odorous molecules in air so that the probability of perception is $50 \%$. If the gas is pure, the odour concentration at the perception threshold equals one molecular concentration. If the gas is a complex mixture, the odour concentration at the perception threshold is defined as to equal 1. In France, it is expressed as a dimensionless number while in Europe, it is expressed in "odour units per $\mathrm{m}^{3 \text { "; }}$, the odour unit, symbolised by "uo", is the quantity of compound that, diluted in $1 \mathrm{~m}^{3}$ of air, leads to the perception threshold.

To bring the odour concentration of the odorous mixture at its concentration at the perception threshold, it has to be diluted with a quantity of pure and therefore odourless air. This is called the "dilution factor at the perception threshold" and it's noted as $\mathrm{K}_{50}$ (refer to Fig. 1). The odour concentration of the mixture is therefore $\mathrm{K}_{50}$ times higher than 
its concentration at the perception threshold. Since the latter equals 1 uo. $\mathrm{m}^{-3}$, the odour concentration of the odorous gas $\left(\mathrm{C}_{\text {odour }}\right)$ is finally directly indicated by the value of $\mathrm{K}_{50}$ that is necessary to measure.
In France, the method to measure the dilution factor at the perception threshold $\mathrm{K}_{50}$ is described in standard NF X 43-101 [1]. The method, based on sensory analysis, uses a panel such as described above.

Table I. Comparison of the different variables measured in olfactometry.

\begin{tabular}{ll} 
Variable & \multicolumn{1}{c}{$A$ - "Odour concentration" } \\
\hline Definition & The odour concentration \\
corresponds to the concentration \\
of an odorous mixture wich is \\
brought to the perception threshold \\
when it's diluted with a quantity \\
$\mathrm{K}_{50}$ of odourless air. The odour \\
concentration at the perception \\
threshold is a dimensionless \\
number equal to 1 for the panel. \\
$\mathrm{K}_{50}$ is called "dilution factor at the \\
perception threshold".
\end{tabular}

"Measurement Panel of pre-selected individuals.

Tool"

Complementary - System of gas dilution

Apparatus (= "olfactometer").

- Prefer the dynamic olfactometer with 3 masks for the AFNOR forced choice method.

Measurement $\quad$ Value of $\mathrm{K}_{50}$ for each expert.

Principle

- Statistical processing $\Rightarrow$ mean and standard deviation for the panel.

French Standard AFNOR NF X 43-101 (+ NF X 43-104 for the sampling).
- The odour intensity of an atmosphere is the extent of the sensation for a concentration of stimulus exceeding that corresponding to the perception threshold.

- Warning, there is no idea of annoyance here. The variable is purely quantitative.
- The odour annoyance is the discomfort felt by an individual as a result of the odours that he perceives.

- This concept includes the quantitative aspect found in the two previous variables as well as another so-called "hedonist" aspect concerning the idea of well-being. That means that a more or less annoying characteristic is associated with the odour perceived.

Panel of pre-selected individuals. Volunteers from the local population, without selection.

- Intensity scale as a reference. - Annoyance scale as a reference.

- Prefer an odour scale (as opposed to a colour, noise, digital, etc. scale).

- Value of the intensity of the odour for each expert.

- Statistical processing $\Rightarrow$ mean and standard deviation for the panel.

- Prefer a verbal scale (as opposed to a digital or graphic scale) with a first "filter" question.

- Level of odour annoyance for each volunteer.

- Statistical processing $\Rightarrow$ mean and standard deviation for the whole of volunteers.

AFNOR NF $X$ 43-103

No French standard.

(+ NF $X$ 43-104 if there is sampling).

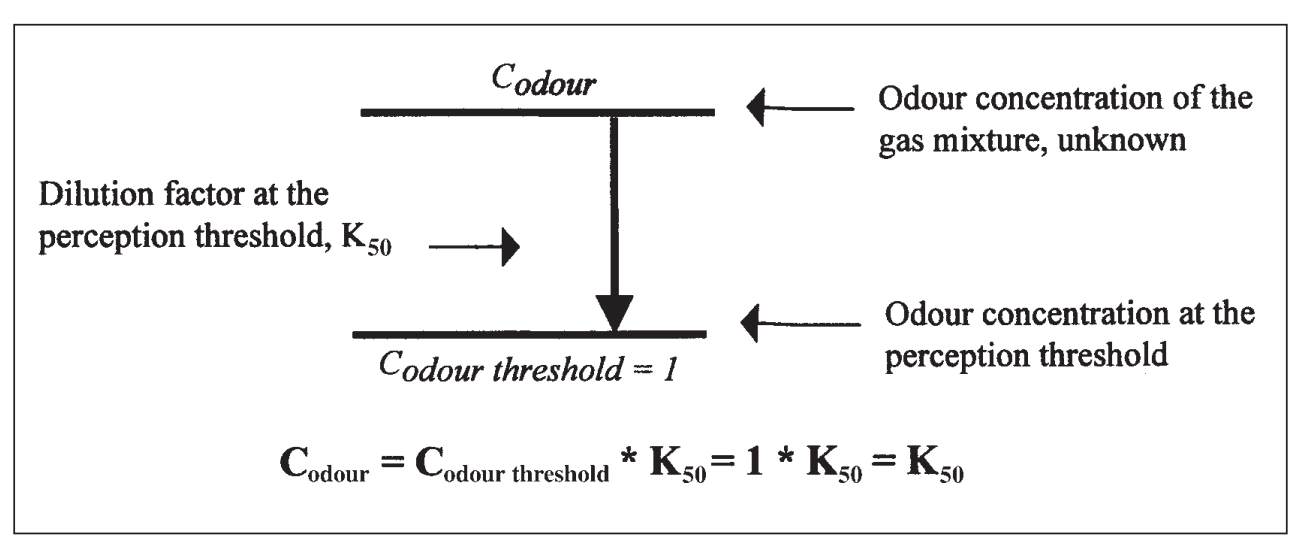

Figure 1. Odour concentration of gas mixture.

ANALUSIS, 2000, 28, N 3 (c) EDP Sciences, Wiley-VCH 2000 


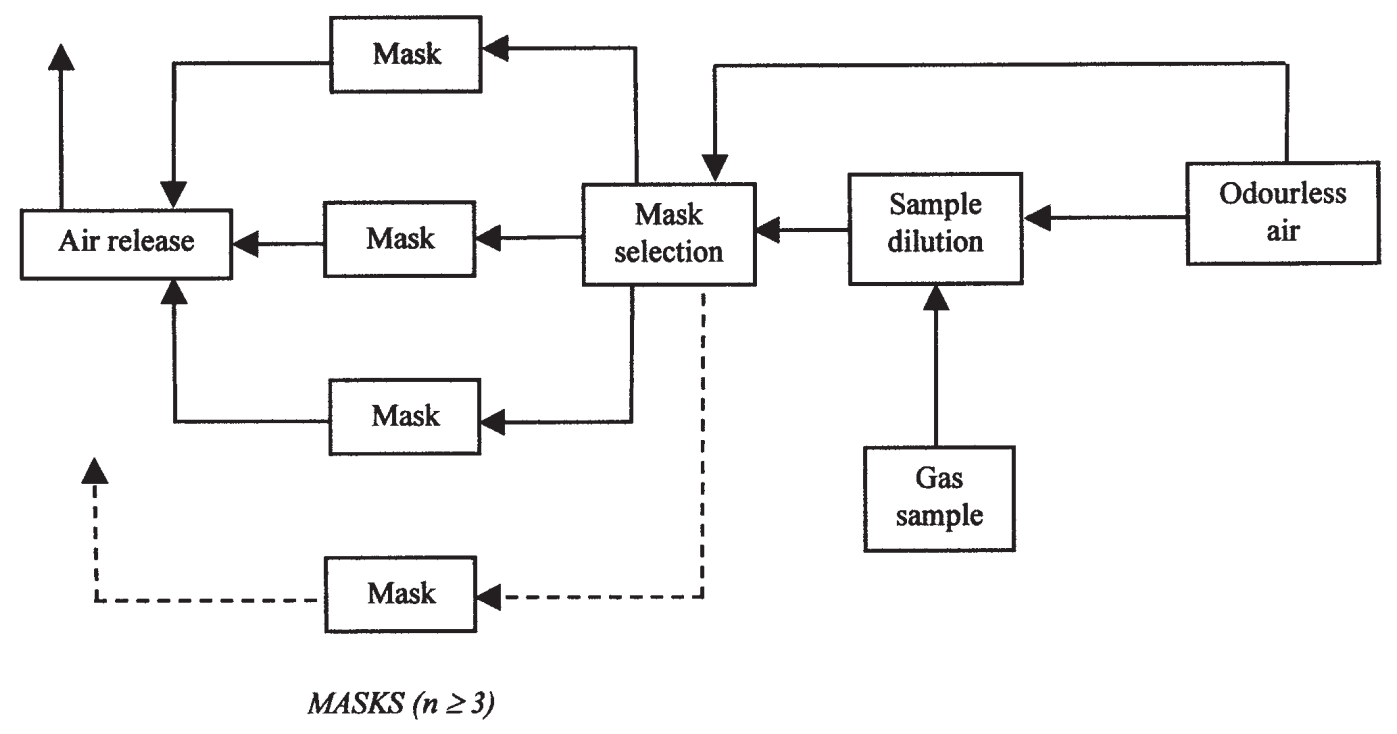

Preferably use a more reliable dynamic olfactometer. The characteristics required for this device are described in standard AFNOR NF X 43-101. The rate of dilution should vary quickly from 10 to 100000 . The interface olfactometer-nose should enable sniffing and avoid the admission of air. It is made of little absorbent materials and a three-" masks" device is particularly recommended due to the so-called "forced choice" method. The recommended output rate is about $2 \mathrm{~m}^{3} \cdot \mathrm{h}^{-1}$ per mask.

Figure 2. Functional diagram of a dynamic olfactometer.

The $\mathrm{K}_{50}$ is determined by presenting each of the members of the panel with the gas sample that has undergone more or less substantial dilutions. This involves the use of an olfactometer (refer to figure 2). This device has two functions: the first is to dilute the gas sample with odourless air and the second is to present the diluted sample to the expert in conditions compatible with olfactory comfort (velocity, pressure, and temperature of the gas presented).

Standard NF X 43-101 exactly describes the protocol for the presentation of dilutions to the panel members. For each of them, the $\mathrm{K}_{50}$ is estimated by the random presentation of a pre-established series of dilutions distributed in geometric progression at intervals of $\sqrt{2}$. They are calculated from a dilution near the perception threshold so as to obtain a dilution for which the panel member detects the odour fairly well, a dilution in which he does not detect the odour for all intents and purposes, and an intermediate dilution. These dilutions are delivered in one of the three masks of the olfactometer (interface between nose and dilution system). The other two masks are only supplied with odourless air. After sniffing, the assessor has to indicate if one of the channels has an odour and which one. The forced choice method is used, that means doubts are not allowed. In case of hesitation, the assessor has to choose by chance. Statistical processing of all of the answers by the expert is used to determine its individual dilution factor at the perception threshold. The statistical processing of the answers of each of the panel members then provides the dilution factor at the perception threshold of the panel $\left(\mathrm{K}_{50}\right)$, as well as the standard deviation related to inter-individual differences.

\section{Odour intensity}

The odorous intensity of an atmosphere is the extent of the sensation for a concentration of the stimulus greater than that corresponding to the perception threshold. The odorous intensity is most often an increasing function of the concentration of the odorous mixture until saturation.

In France, the method to measure the intensities of odour is described in standard NF X 43-103 [2]. As above, the method is based on sensory analysis. It relies on a panel, which smells the gas atmosphere. The gas studied is either a sample taken according to standard NF X 43-104 or ambient air. There are many methods to assess the odour intensity; only one of these methods, the olfactory equivalence method ("olfactory matching"), currently used in industrial practice, is recommended in standard NF X 43-103.

This method is based on the use of a reference series made of odour intensities (refer to figure 3). It consists of several gas samples containing known concentrations of 
Principle: the odour intensity of an atmosphere can be measured by comparison with an odour scale taken as a reference (as opposed to no scale at all or colour, noise, digital scale...): this is called the « olfactory equivalence method».
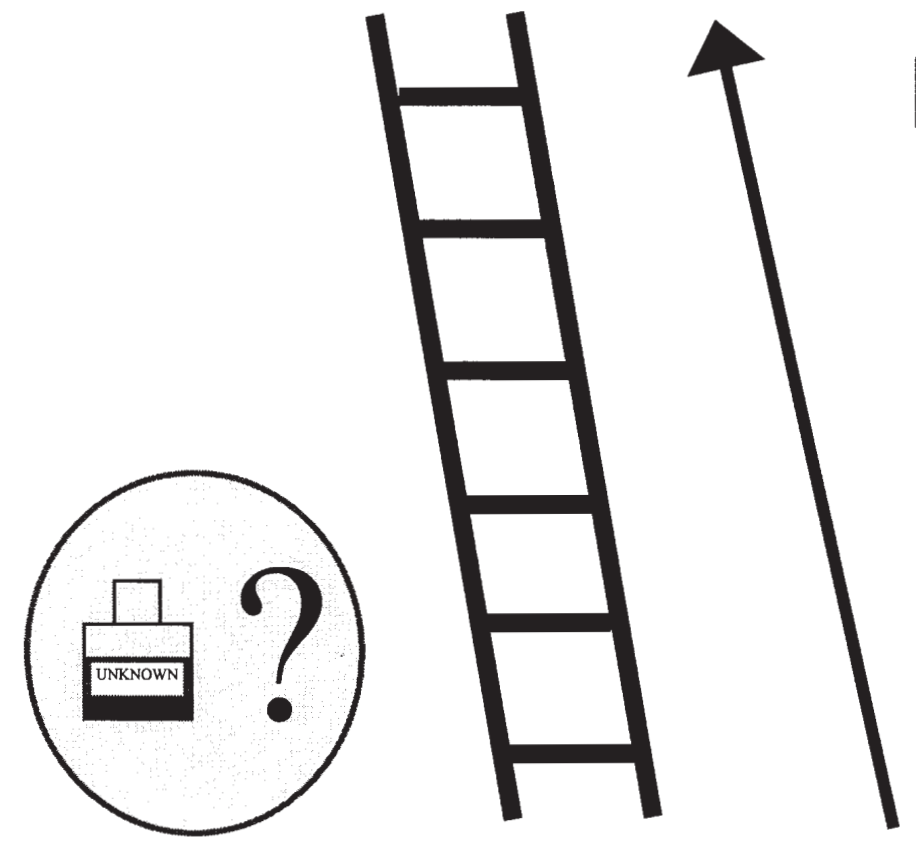
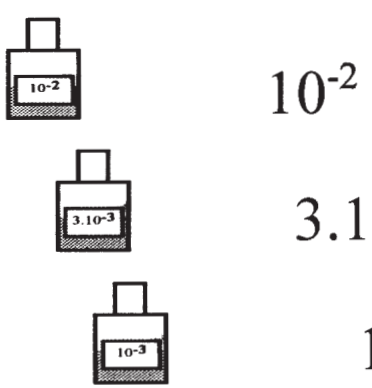

$3.10^{-3}$

$10^{-3}$

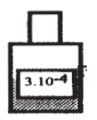

$3.10^{-4}$

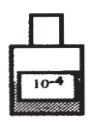

$10^{-4}$

$3.10^{-5}$

Figure 3. Measurement of odour intensities by the olfactory equivalence method.

butan-1-ol or pyridine. The measurement has to evaluate the odour intensity of the stimulus by comparison with the odour intensities of the reference samples. The intensity values provided by each of the members of the panel are expressed in equivalent concentrations of butan-1-ol or pyridine in air. These values are given in logs since the stimulus-sensation relationship is an exponential law ("Stevens law"). The statistical processing of the answers from each of the panel members is used to calculate the geometric mean of the odour intensity and the standard deviation related to the inter-individual differences observed between the members of the panel.

\section{Odour annoyance}

Odour annoyance is felt by an individual because of the odours that he perceives. It is necessary to note that odour annoyance not only includes the quantitative aspect found in the two variables previously seen but also the so-called "hedonist" aspect. This takes into account the idea of well being, thereby associating an agreeable or disagreeable character to the odour perceived. This new concept involves psycho-sociological phenomena and is closely related to the history of the individual concerned, his culture, etc. For example, an agreeable odour for a European isn't necessarily one for an Asian and vice versa.
A panel is used to assess the level of odour annoyance: this time it doesn't consist of pre-selected experts but of volunteers, chosen from among the local population. In France, there are no standards concerning this type of measurement, developed in Northern Europe by a research team from the University of Utrecht [8].

The measurement involves questioning volunteers for their opinion about the level of odour annoyance: they write their response on a form filled at a given time of the day and during a determined period that may last for several months (refer to figure 4). For each observation, meaning in one day and at a given time, the individual answers are used to calculate an odour annoyance index. Ranging from 0 to 100 , the odour annoyance index is zero when no one is bothered by the odours and equals 100 when all of the participants are extremely bothered.

Two other methods are sometimes used: complaints collection or opinion surveys concerning periods more or less in the past (several days to several months). The advantages of the odour annoyance study described above, compared with the other methods are: the levels of odour annoyance that volunteers provide are only based on their immediate experience and does not rely on the memory of past episodes whose objectivity is strongly called into question, every volunteers work with the same scale of responses to indicate 
Volunteer number :

Please smell carefully and answer the question.

Do you smell an odour? No

Yes

When you smell this odour, are you :

1. Not annoyed?

2. Not very annoyed?

3. Annoyed?

4. Very annoyed?

5. Extremely annoyed?
Figure 4. Type of form filled in during an annoyance study [8]. the level of odour annoyance, the episodes during which the subjects have to give an opinion can be controlled by the operator and correlated with levels of odorous pollution.

\section{Application to industrial odour problems}

\section{Study of the sources of odour}

The odour concentration is a variable characteristic of the effluent studied. It is preferably applied to gas sampled at the source, before any uncontrolled dilution in the outside atmosphere (before leaving the release stack or in the ambient air of the odorant building).

For a full characterisation of the source (refer to figure 5), its "odorant flow rate" $\left(\mathrm{Q}_{\text {odour }}\right)$ is calculated. It corresponds to the odour concentration $\left(\mathrm{C}_{\text {odour }}\right)$ multiplied by the gas flow rate $\left(\mathrm{Q}_{\text {gas }}\right.$, in $\left.\mathrm{m}^{3} \cdot \mathrm{h}^{-1}\right)$. It is expressed in uo. $\mathrm{h}^{-1}$ or in $\mathrm{m}^{3} \cdot \mathrm{h}^{-1}$ according to whether the odour concentration is given in uo. $\mathrm{m}^{-3}$ or as a dimensionless number.

In practice, in the case of regulation controls, the odorant flow rates obtained for the studied sources are compared with the limit values provided in the legislation.

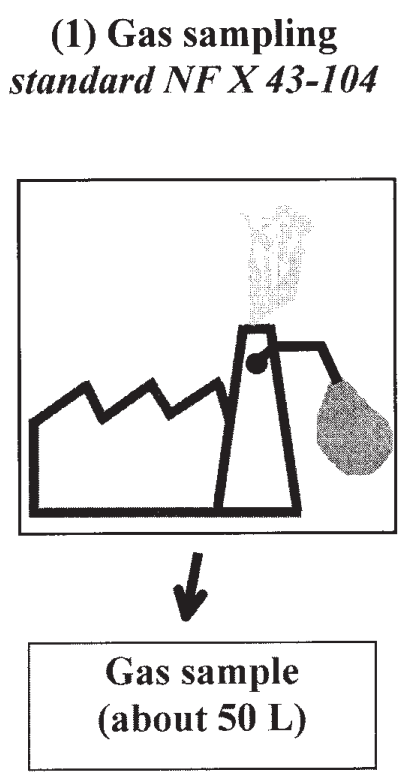

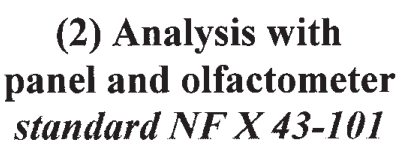
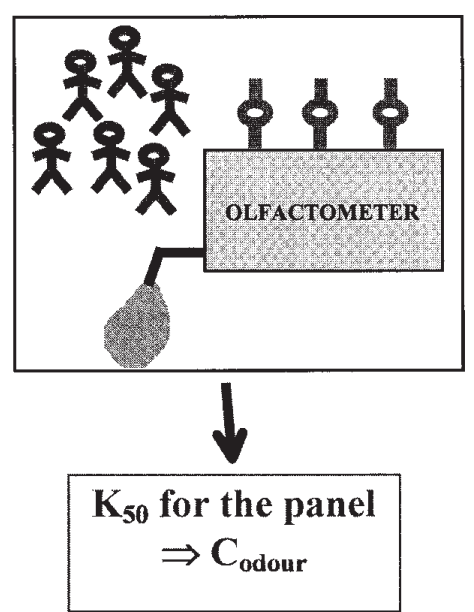

(3) Calculation of the « odorant flow rate ", ( $\left.Q_{\text {odour }}\right)$

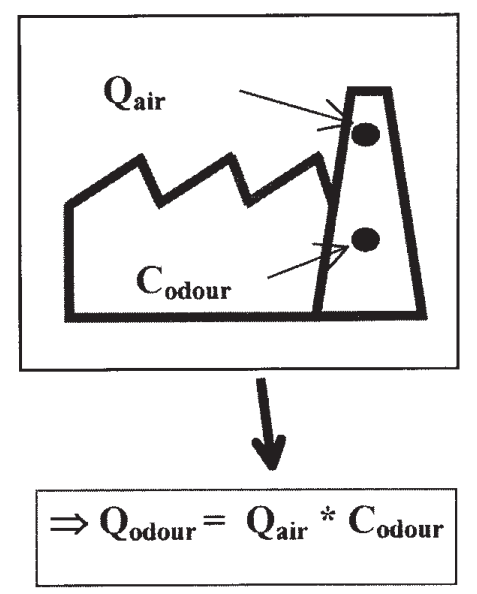

Figure 5. Characterization of an odour source: three parts. 
Another application consists of using the odorant flow rates to compare and rate the different odorous emissions from an industrial site. An interesting complement is to rate the different sources of odour, not only according to the quantity of odour given off but also as a function of their impact on the environment. To do so, the atmospheric dispersal of the odorous gas wreath is calculated (example of calculation code: ICAIR3C developed at the French Nuclear Safety and Protection Institute, "IPSN"). In particular, calculation of the odour concentration at the ground as a function of the distance from the source is used to assess the zones where the odours are perceptible by the neighbours. Therefore, comparison of the calculated perception zones is a manner to compare the consequences of the sources on the environment and to rate them. Later, the industrialist can use it to direct choices concerning the odour control of the gaseous effluents. One example of such comparison is given on the Form $n^{\circ} 1$.

\section{Form $n^{\circ} 1$ : characterization of odour sources}

Object of the study: annual control, imposed by an administration, of the odorant gaseous effluents emitted by two processes $A$ and $B$ of a factory located in Alsace (France, 67), with checking of the efficiency of the odour control system set at the exit of the process $B$.

\section{Processes:}

process A: channelled gas effluent, emission height $=10 \mathrm{~m}$, flow rate $Q_{\text {air }}=6000 \mathrm{~m}^{3} \cdot \mathrm{h}^{-1}$;

process B: emitting surface with aeration (biofilter), size $8 \mathrm{~m}$ by $20 \mathrm{~m}$, flow rate $\mathrm{Q}_{\text {air }}=30000 \mathrm{~m}^{3} \cdot \mathrm{h}^{-1} \mathrm{or}^{231} \mathrm{~m}^{3} \cdot \mathrm{h}^{-1} \cdot \mathrm{m}^{-2}$.

\section{Méthodologies: (1) sampling of odorants}

- process A: channelled source $\rightarrow$ sampling with a probe introduced in the release stack, for conditions of production chosen by the industrialist; sampling carried out on the 25.10 .98 between 8.45 am and 9.00 am;

- process B - downstream from the biofilter: aerated emitting surface (= biofilter surface) $\rightarrow$ sampling with a probe introduced in the mobile hood (protection from the influence of the wind) of the gas given off by the surface of the biofilter; sampling carried out on the 25.10 .98 between 9.50 am and 10.10 am; sampling points chosen by the industrialist, after physico-chemical analysis carried out in several points of the surface;

- process B - upstream from the biofilter (for the assessment of the odour control efficiency): channelled source $\rightarrow$ sampling with a probe introduced in the duct which supply the biofilter with air; sampling carried out on the 25.10 .98 between $11.15 \mathrm{am}$ and $11.30 \mathrm{am}$.

The samples are transported in an air-conditioned vehicle to the laboratory located in the CEA at Saclay (France-91) on the day of their sampling in order to be analysed at the latest on the next day.

\section{Methodologies: (2) Olfactometric analysis}

- During the 24 and 30 hours after sampling

- At the laboratory (cheaper and more rigorous than taking the panel and the olfactometer to the site)

- Panel: 6 members, selection as described in standard reference NF X 43-101

- Dilution device: properly calibrated olfactometer

- Analyse procedure according to the standard NF X 43-101

Results of the measurement

\begin{tabular}{|c|c|c|c|c|c|c|}
\hline & \multicolumn{2}{|c|}{ process $A$} & \multicolumn{2}{|c|}{$\begin{array}{c}\text { process } B \\
\text { downstream biofilter }\end{array}$} & \multicolumn{2}{|c|}{$\begin{array}{c}\text { process } B \\
\text { upstream biofilter }\end{array}$} \\
\hline expert $n^{\circ} 1$ & $\underset{3,56}{\log K_{50}}$ & $\begin{array}{l}\mathbf{K}_{50} \\
3622\end{array}$ & $\underset{3,00}{\log K_{50}}$ & $\begin{array}{l}\mathbf{K}_{50} \\
1002\end{array}$ & $\underset{4,16}{\log K_{50}}$ & $\begin{array}{c}\mathbf{K}_{50} \\
14489\end{array}$ \\
\hline expert $n^{\circ} 2$ & 4,01 & 10209 & 3,48 & 3027 & 4,13 & 13522 \\
\hline expert $n^{\circ} \overline{3}$ & 4,02 & 10446 & 3,36 & 2296 & 4,34 & 21930 \\
\hline expert $n^{\circ} 4$ & 3,71 & 5116 & 3,76 & 5768 & 4,45 & 28251 \\
\hline expert $n^{\circ} 5$ & 4,18 & 15100 & 3,70 & 5024 & 4,45 & 28251 \\
\hline expert $n^{\circ} 6$ & 3,87 & 7396 & 3.74 & 5508 & 4,59 & 38997 \\
\hline $\begin{array}{l}\text { Mean for } \\
\text { panel }\end{array}$ & $\begin{array}{c}3,89 \\
\text { standard deviation }\end{array}$ & 7774 & $\begin{array}{c}3,51 \\
\text { standard deviation }\end{array}$ & 3219 & $\begin{array}{c}4,35 \\
\text { standard deviation }\end{array}$ & 22613 \\
\hline
\end{tabular}


- The results obtained with the panel of 6 experts are supposed to be representative of the whole of the standard population. The standard deviation obtained shows that, for the sample issued from the process $A$, the dilution factor at the perception threshold is:

$\Rightarrow$ contained between 4612 and $13104\left(=K_{16}\right.$ and $\left.K_{84}\right)$ for $68,26 \%$ of the population and,

$\Rightarrow$ contained between 2794 and $21631\left(=K_{2,5}\right.$ and $\left.K_{97,5}\right)$ for $95 \%$ of the population.

In the same way, for the sample taken downstream from the biofilter (process $B$, with treatment), the dilution factor at the perception threshold is:

$\Rightarrow$ contained between 1632 and $6348\left(=K_{16}\right.$ and $\left.K_{84}\right)$ for 68,26\% of the population and,

$\Rightarrow$ contained between 850 and $12183\left(=K_{2,5}\right.$ and $\left.K_{97,5}\right)$ for $95 \%$ of the population.

At least, for the sample taken upstream from the biofilter (process B, without treatment), the dilution factor at the perception threshold is:

$\Rightarrow$ contained between 14938 and $34232\left(=K_{16}\right.$ and $\left.K_{84}\right)$ for 68,26\% of the population and,

$\Rightarrow$ contained between 10033 and $10969\left(=K_{2,5}\right.$ and $\left.K_{97,5}\right)$ for $95 \%$ of the population.

- The mean odour concentrations $\left(\mathrm{C}_{\text {odour }}\right)$ and the corresponding odorant flow rates $\left(\mathrm{Q}_{\mathrm{odour}}\right)$ are given in the next table.

\begin{tabular}{|c|c|c|c|}
\hline Source & $\begin{array}{l}C_{\text {odour }}\left(=K_{50} * 1\right) \\
\text { (dimensionless) }\end{array}$ & $\begin{array}{c}Q_{\text {air }} \\
\left(m^{3} \cdot h^{-1}\right)\end{array}$ & $\begin{array}{l}Q_{\text {odour }} \\
\left(m^{3} \cdot h^{-1}\right)\end{array}$ \\
\hline process A & 7774 & 6000 & $4,7.10^{7}$ \\
\hline $\begin{array}{l}\text { process } \mathrm{B} \text {, after treatment } \\
\text { (downstream biofilter) }\end{array}$ & 3219 & 30000 & $9,7.10^{7}$ \\
\hline $\begin{array}{l}\text { process } B \text {, without treatment } \\
\text { (upstream biofilter) }\end{array}$ & 22613 & 30000 & $6,78 \cdot 10^{8}$ \\
\hline
\end{tabular}

- The odour concentration of the effluents from the process $A$ is twice higher than the one from the process $B$ after treatment. Nevertheless, the flow rate emitted by the process $A$ is five time lower than in the case of the process $B$. Then, the odorant flow rate emitted by the process $A$ is at the end lower than for the process $B$ after treatment.

- The odour control efficiency of the biofilter, equal to $86 \%$, can be considered as quite good. But note that the odorant flow rate before treatment in the biofilter is rather high so that the downstream odorant flow rate is still quite important.

- The odour concentration at the ground obtained by atmospheric dispersion calculation for the process $A$ and $B$ after treatment provides the "odour perception area" (in this example, good diffusion conditions and wind velocity equal to 4 $\mathrm{m} . \mathrm{s}^{-1}$ are used):

\begin{tabular}{lccc}
\hline Source & $\begin{array}{c}Q_{\text {odour }} \\
\left(\mathrm{m}^{3} \cdot \mathrm{h}^{-1}\right)\end{array}$ & $\begin{array}{c}\text { Effective emission } \\
\text { height }\end{array}$ & $\begin{array}{c}\text { Odour perception } \\
\text { area }\end{array}$ \\
\hline process A & $4,7.10^{7 *}$ & 14 & until $600 \mathrm{~m}$ \\
process B after treatment & $9,7.10^{7}$ & 0 & until $900 \mathrm{~m}$ \\
\hline
\end{tabular}

*effective emission height is a function of the wind and of emission height, temperature and velocity of the gazeous effluent

${ }^{* *}$ that means zone where $C_{\text {odour }}$ at the ground is higher than $C_{\text {threshold odour }}=1$

These results show that the process $B$ deodorized is more bad in terms of impact on the environment than process $A$, the odours of wich are not perceived any more after $600 \mathrm{~m}$.

\section{Study of the environment of a source}

Independent of the calculations indicated above, it is possible to assess the impact of a source of odour on its environment after taking measurements, at different points on the site, of the levels of odour or the level of odour annoyance.
The level of odour in the environment is provided by the measurement of odour intensity. These measurements are made at different points in space on the ambient air. The odorous intensities are determined with a panel; one example of such a measurement is given in the Form $n^{\circ} 2$. 


\section{Form $n^{\circ} 2$ : environment of an odour source Odourous intensities in the environment}

Object of the study: observe if odours emitted by an industrial site can be perceived in its environment. If it's possible, quantify the odour level as a function of the distance from the industrial site.

\section{Procedure}

Type of activity : pigs rearing.

Type of measurement : odour intensity, as described in standard reference NF X 43-103.

Panel : 7 members, selection as described in standard reference NF X 43-103.

Duration : 1 day, during wich wind direction was the most interesting for this study, meaning a North-East wind.

Measurement frequency : 15 points per travel and several travel in a day.

Meteorological data : bought to Météo-France.

\section{Results}

(1) odour intensities measured for each travel at each point with indication of the origin of the odour (natural, human/town, industrial, agricultural).

- at a certain point, the odour perceived is associated to an intensity level and to an origin.

- at a certain point, several odours from differents origins can be perceived.

- at a certain point, one can smell no odour.

(2) Synthesis on results map

$\Rightarrow$ the rectangles number 12,13 , 14 and 15 indicate the odour coming from the studied pigs rearing (located at point 14 );

$\Rightarrow$ the results show that these odours can be perceived at very strong or mean levels (rectangles 15 and 13) when the panel is near the farm (points 14 and 22);

$\Rightarrow$ and that these odours can be perceived at the begining of the village (point 28) at low or mean levels (rectangles 12 and 13).

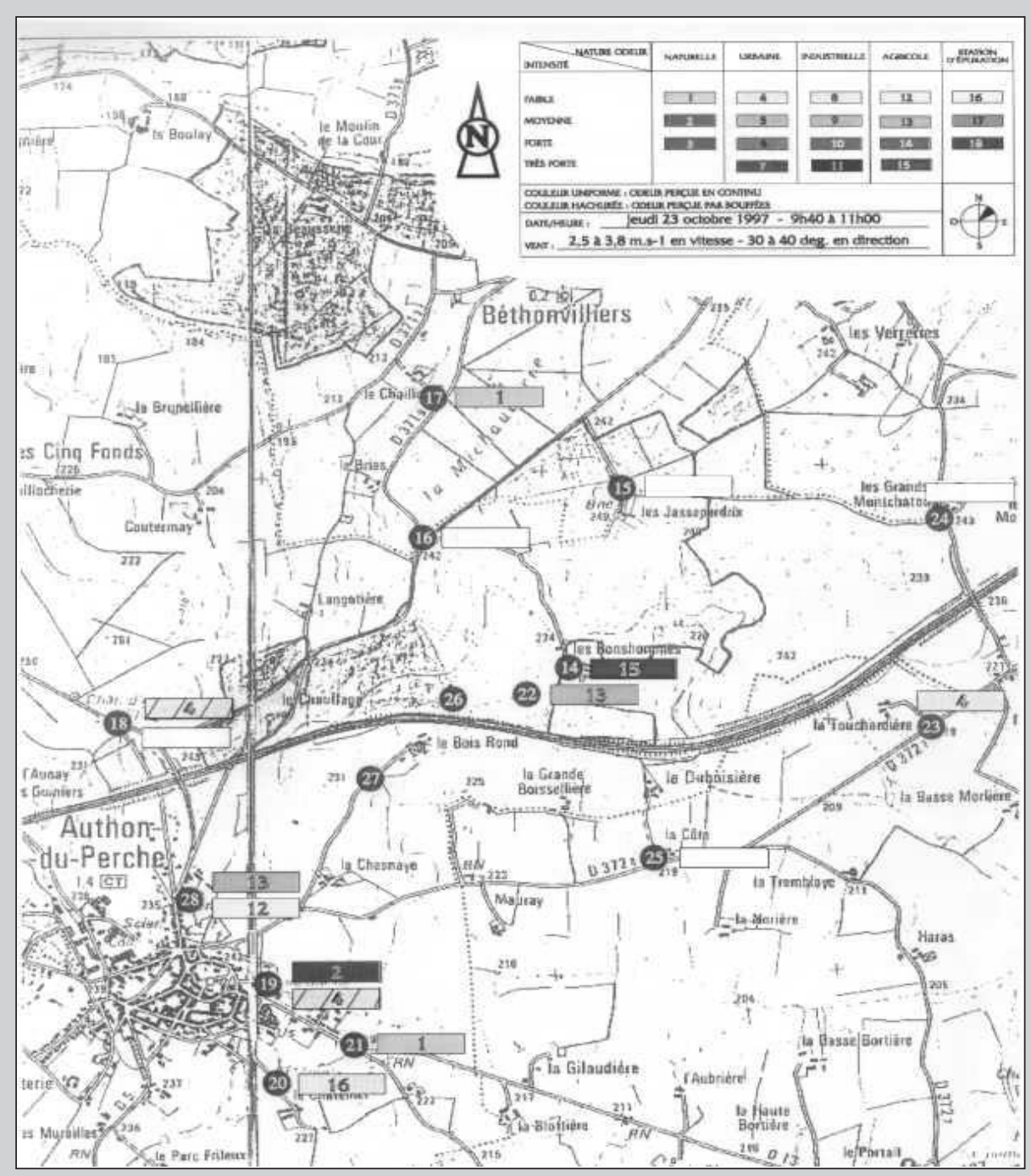




\section{Form $\mathrm{n}^{\circ}$ 3: environment of an odour source Odour annoyance of the neighbouring population of an industrial site}

Object of the study: assess the level of odour annoyance of the local population as a function of time and space.

\section{Procedure}

Place: French city.

Type of measurement: odour annoyance level.

Panel: 400 volunteers, no selection.

Duration: 1 year.

Measurement frequency: during 51 weeks: 2 measures a week; Wednesday at 9 am and Saturday 8 pm.

- during 4 days: 2 measures a day, morning and afternoon.

- responses written on answer-form sent to the IPSN

Meteorological data: scanned during all the measurement campaign

\section{Results}

(1) Participation rate

- it is check all along the study

- members the number of responses of wich is under $20 \%$ of expected one are excluded

- global participation rate: $70 \%$; that means a good motivation of the panel

(2) Odour annoyance index

- it is calculated from the individual answers of the volunteers

- odour annoyance index can be a function of time for a given area (indicates the intensity and the frequency of the odour annoyance) (see examples on the two following pictures)
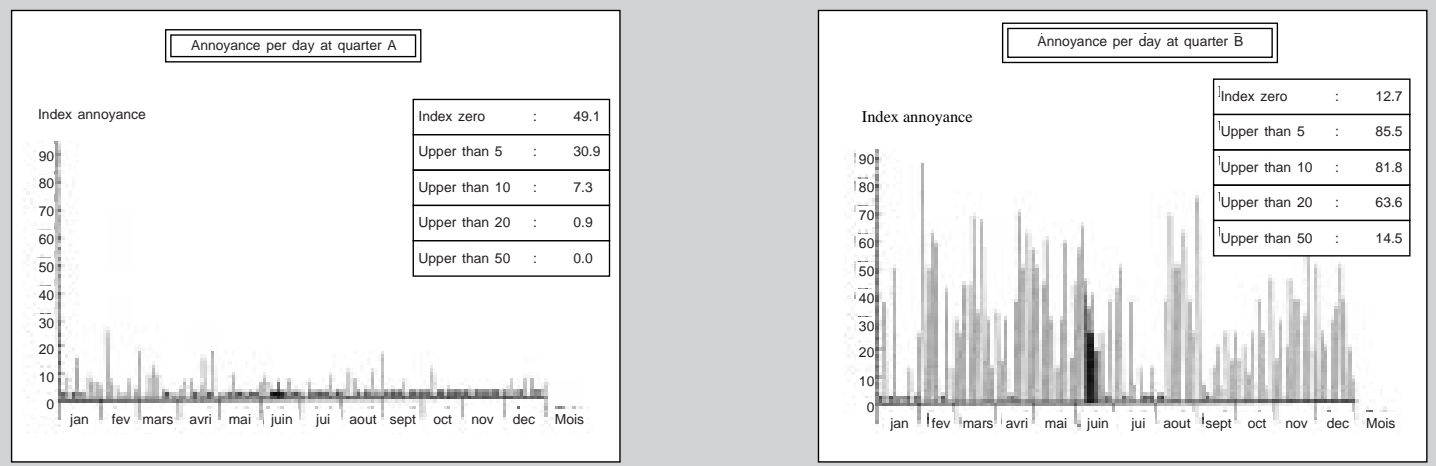

$\Rightarrow$ for the two areas, the odour annoyance index seem to vary with time.

$\Rightarrow$ the index values are low for the "quarter A" (lower than 20 in general) and very often high for the "quarter B" (between 10 and 70 most of time).

- odour annoyance index can be a function of the direction for a given period (indicates the provenance of the annoying odorant flow rates and the odour annoyance intensity per direction where annoyance indexes are proportional to the lenght of the sticks). (See two examples on the pictures corresponding to two distinctes zones).
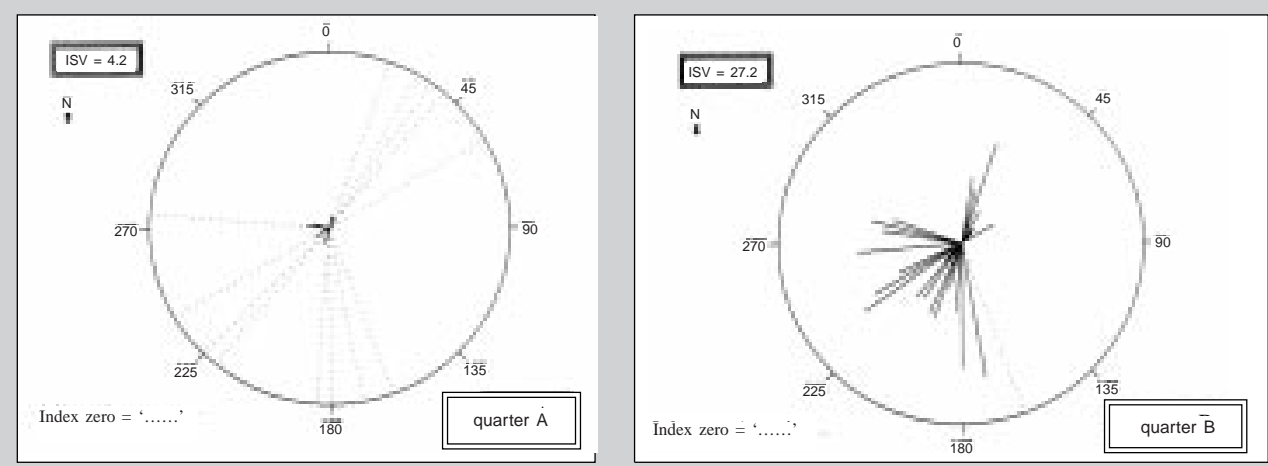

*ISV indicates mean annoyance index for wind velocities lower than $1 \mathrm{~m} . \mathrm{s}^{-1}$ ** dotted line indicates annoyance index equal to zero

$\Rightarrow$ for zone called "quarter A", annoyance is low (shorts sticks) as seen just before and it comes from south-west or north-east zones;

$\Rightarrow$ for zone called "quarter B", annoyance is more high (longer sticks) as seen just before and it comes from the same directions as in the case of quarter A (south-west and north-east zones). 


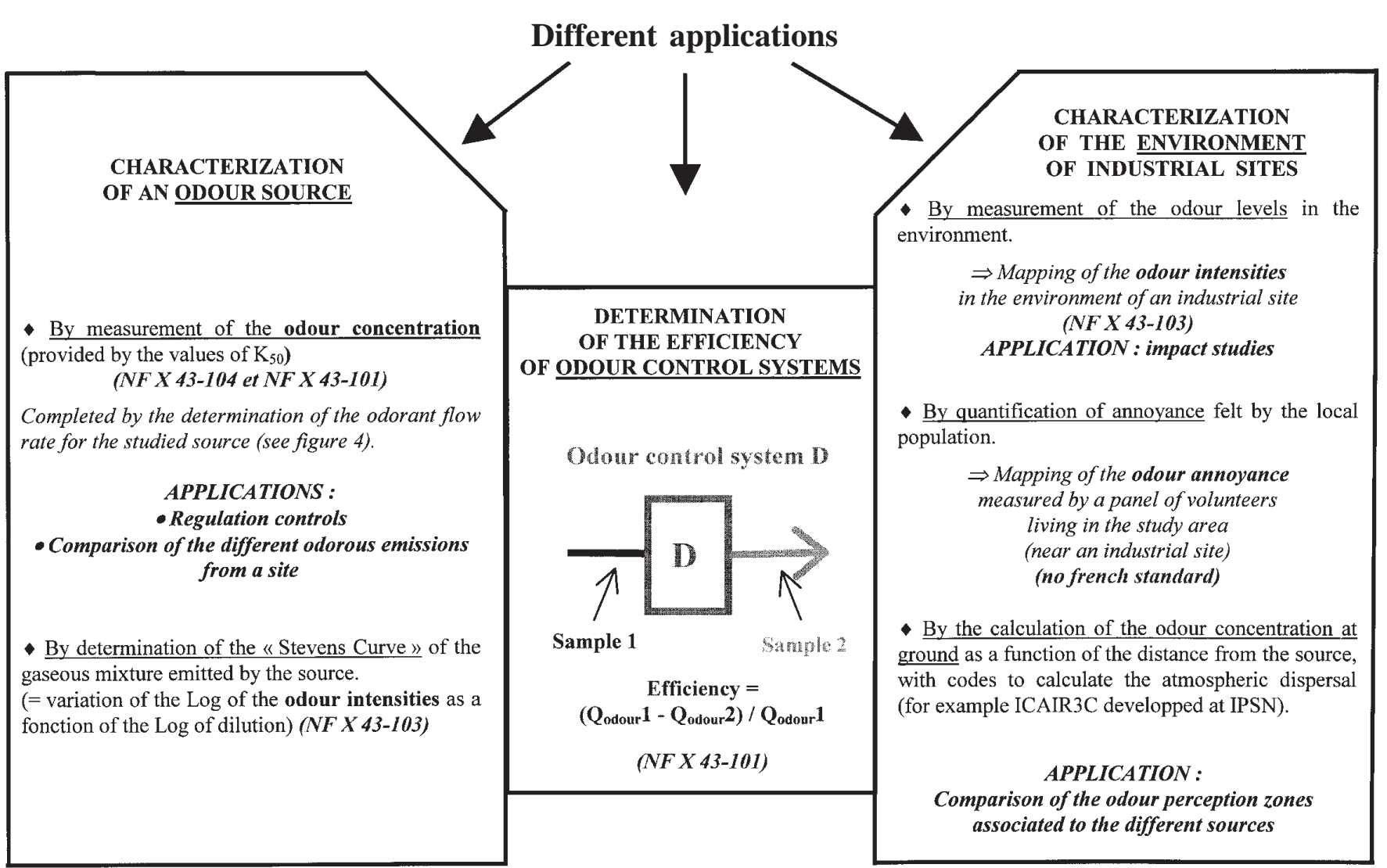

Figure 6. Applications of the olfactometric measurement: recapitulatory.

In practice, in France, this type of measurement may be carried out in the impact studies required of industries when they get established on a site or when they request authorisation to increase their productive capacity. For a given site, comparison of its odorous states before and after the installation or extension of a plant is used to reveal the appearance of any odour due to this plant.

The measurement of annoyance is used to draw up maps of the levels of odour annoyance in the environment of an industrial site. This was carried out by IPSN at the "Étang de Berre" [9], the Estuary of the Seine [10], the North coast and the Rhine [11]. In practice, this may be carried out upon request by an administration that wants to orient an approach for the odour control of certain of its industrial sites. One example is given in the Form $n^{\circ} 3$.

\section{Characterisation of an odour control system between the source of odour and the environment}

Comparison of the odorant flow rate emitted by an installation, with and without odour treatment respectively, is used to realistically assess the efficiency of the odour control system (see example on Form $\mathrm{n}^{\circ} 1$ ). In fact, this is never directly provided by the efficiency of the system to eliminate certain molecules.

\section{Conclusion}

Olfactometry, or the measurement of odours by sensory analysis, offers great many applications in the field of air pollution by odours of industrial origin. It allows for the study of complex gaseous effluents and provides objective results taking into account the differences in olfactory perception that naturally exist among individuals.

Several variables can be measured. Some of them have been standardised in France: odour concentration given by the value of the dilution factor at the perception threshold (standard NF X 43-101), odour intensity (standard NF X 43-103), odour annoyance (not standardised in France). These variables are used (refer to figure 6) to characterise a gas effluent at the source, compare the different sources of odour, assess the efficiency of odour control system, experimentally and theoretically assess the impact of an industrial site emitting odours on its environment, assess the odour annoyance near an industrial site.

\section{References}

1. Norme AFNOR NF X 43-101, Qualité de l'air. Mesurage de l'odeur d'un effluent gazeux. Détermination du facteur de dilution au seuil de perception, 1986. 
2. Norme AFNOR NF X 43-103, Qualité de l'air. Mesurage de l'odeur d'une atmosphère gazeuse. Méthode supraliminaire, 1996.

3. Norme AFNOR NF X 43-104, Qualité de l'air. Atmosphères odorantes. Méthodes de prélèvement, 1984.

4. Perrin, M.-L.; Jézéquel, M.; Thal, M.-F. Congrès APCA'88, Dallas (Texas), 21-24 June 1988.

5. Perrin, M.-L.; Thal, M.F.; Zettwoog, P. Techniques de l'Ingénieur, 1991, P-445, 1-8.

6. Le Cloirec, P.; Perrin, M.L. In : Odeurs et désodorisation dans l'environnement; Martin,G.; Laffort, P. Eds, Paris: Tec \& Doc Lavoisier, 1991, pp 247-264.
7. Gouronnec, A.M. Afite, recueil des textes des conférences; 1998, pp 31-41.

8. Kôster, E.P. In : Odeurs et désodorisation dans l'environnement; Martin, G.; Laffort, P. Eds, Paris: Tec \& Doc Lavoisier, 1991; pp 61-78.

9. Perrin, M.-L.; Jézéquel, M.; Delpeuch, J.-L.; Nadal, R. 8ème Congrès mondial sur l'air pur et exposition, La Haye (The Netherlands), 11-15 september 1989.

10. Perrin, M.-L.; Quéré, S.; Huchet, N.; Delmas, V.; Ledenvic, P. Pollution Atmosphérique 1994, 141, 66-73.

11. Perrin, M.-L.; Quéré, S.; Target, A.; César, F. In Proceedings of the 10th World Clean Air Congress; Tolvanen, M.; Antilla, P.; Kämäri, J. Eds; 1995, vol. 2, p 261. 